\title{
ANÁLISE COMPARATIVA ENTRE OS MÉTODOS DE AVALIAÇÃO UTILIZADOS NO CURSO SUPERIOR DE TECNOLOGIA EM REDES DE COMPUTADORES
}

Ronaldo Toshiaki Oikawa, Cristiane Maciel Rizo

Universidade do Oeste Paulista - UNOESTE

\section{RESUMO}

Este estudo culminou na tradução de esforço e enriquecimento teórico associado com a prática implantada no nascimento e vida do curso, em conjunto com todo o corpo docente e o Ambiente Virtual de Aprendizagem (AVA). A iniciativa, interatividade, interdisciplinaridade, mediação pedagógica e avaliação pedagógica, expressa a abordagem de um tema atual e da maior importância, posto que no futuro próximo o próprio Ministério da Educação (MEC) corrobora para que as disciplinas e os cursos trabalhem parcialmente à distância, ou mesmo totalmente à distância. Com isso, cada vez mais, o papel da educação tenha significado e expressividade no panorama educacional brasileiro, em razão do desenvolvimento de atividades e teorias que possam contribuir para melhorar e impulsionar o emprego da moderna tecnologia da informação e de comunicação a serviço da inovação educativa. O campo dessa pesquisa está focado no Curso Superior de Tecnologia de Redes de Computadores, delineando-se no propósito de desvelar como a mediação pedagógica, avaliação diagnóstica e formativa é concebida e realizada nos âmbitos presenciais e ambiente virtual de aprendizagem (AVA). Ao longo do texto, é apresentada a contribuição pessoal, que procura demonstrar as grandes vantagens e melhorias realizadas ao longo do ciclo do curso, e a existência de atores (docentes) qualificados no formato didáticopedagógica, a fim de obter melhores resultados no ensino e aprendizagem do discente.

Palavras-chave: interatividade, mediação pedagógica, avaliação diagnóstica, avaliação formativa, ambiente virtual de aprendizagem.

\section{INTRODUÇÃO}

O presente trabalho tem como tema, Análise Comparativa entre os métodos de Avaliação Utilizados no Curso Superior de Tecnologia em Redes de Computadores. O interesse nesse tema inicia-se a partir das vivências, e anseios de melhorias no ensino e aprendizagem.

Estudar a história e entender a avaliação educacional culminará na verificação da própria avaliação educacional, tanto que nos primórdios a avaliação da aprendizagem surge atrelada ao currículo, ou seja, sequência da escolaridade onde era verificado o aproveitamento escolar como "aprovado" e "reprovado". Devido alto índice de seleção ocasionado por tal ação, no ano de 1960, a Lei de Diretrizes e Bases da Educação Nacional (LDB), mostra em seus artigos, que:

Art. 39. A apuração do rendimento escolar ficará a cargo dos estabelecimentos de ensino, aos quais caberá expedir certificados de conclusão de séries e ciclos e diplomas de conclusão de cursos.

$\S 10 \mathrm{Na}$ avaliação do aproveitamento do aluno preponderarão os resultados alcançados, durante $\mathrm{o}$ ano letivo, nas atividades escolares, 
asseguradas ao professor, nos exames e provas, liberdade de formulação de questões e autoridade de julgamento.

$\S 20$ Os exames serão prestados perante comissão examinadora, formada de professores do próprio estabelecimento, e, se este for particular, sob fiscalização da autoridade competente (BRASIL, 1961).

De qualquer forma, ainda houve vários trabalhos paralelos para tentar contornar a situação do aluno, visto que o artigo 39 da LDB deixa lacunas para a possível recuperação do alunado. Entretanto com a nova reforma educacional promulgada pela LDB 5.692/1971, trouxe modificações importantes para o processo de avalição, principalmente no seguinte artigo:

Art. 14. A verificação do rendimento escolar ficará, na forma regimental, a cargo dos estabelecimentos, compreendendo a avaliação do aproveitamento e a apuração da assiduidade.

$\S 10 \mathrm{Na}$ avaliação do aproveitamento, a ser expressa em notas ou menções, preponderarão os aspectos qualitativos sobre os quantitativos e os resultados obtidos durante o período letivo sobre os da prova final, caso esta seja exigida.

§ 200 aluno de aproveitamento insuficiente poderá obter aprovação mediante estudos de recuperação proporcionados obrigatoriamente pelo estabelecimento.

§ 3o Ter-se-á como aprovado quanto à assiduidade: o aluno de frequência igual ou superior a $75 \%$ na respectiva disciplina, área de estudo ou atividade; o aluno de frequência inferior a $75 \%$ que tenha tido aproveitamento superior a $80 \%$ da escala de notas ou menções adotadas pelo estabelecimento; o aluno que não se encontre na hipótese da alínea anterior, mas com frequência igual ou superior, ao mínimo estabelecido em cada sistema de ensino pelo respectivo Conselho de Educação, e que demonstre melhoria de aproveitamento após estudos a título de recuperação.

$\S 40$ Verificadas as necessárias condições, os sistemas de ensino poderão admitir a adoção de critérios que permitam avanços progressivos dos alunos pela conjugação dos elementos de idade e aproveitamento (BRASIL, 1971).

Nos tempos atuais com a LDB 9.394/96, novas formas de avalição surgem principalmente avaliações tecnológicas, na qual abre precedentes para novas investigações de modelos de avaliação ensino e aprendizagem. 


\section{OBJETIVOS}

Geral

Refletir sobre a história do Curso Superior de Tecnologia em Redes de Computadores e identificar formas de avaliação que estão surgindo na atualidade. Em vista disso, a "Avaliação da aprendizagem", à função de avaliar e favorecer ao aluno o caminho da aprendizagem, culminando na titulação. O prévio conhecimento dos critérios e dos instrumentos de avaliação, que é essencial à conscientização do discente em formação e do docente como avaliador.

\section{Específicos}

a) Identificar formas de avaliações existentes dentro do curso Superior de Tecnologia em Redes de Computadores.

b) Analisar como o Projeto Integrador de Disciplina (PID) e o Projeto Integrador de Tecnologia (PIT) atuam dentro do curso.

c) Analisar as formas gerais avaliativas que se destacam no aprendizado do alunado.

\section{METODOLOGIA}

Tal trabalho teve cunho na pesquisa teórica, na qual estão em pauta vários itens abordados, como a dialética epistemológica do ensino e aprendizagem, fenomenologia e o positivismo. Para tanto, houve o resgate de documentos como o parecer 29 (BRASIL,2001), publicado em 02 de Dezembro de 2002, que o Ministro de Estado de Educação, Prof. Dr. Paulo Renato Souza, através do Aviso Ministerial no 120/2000, encaminhou à deliberação do Conselho Nacional de Educação, nos termos da Lei Federal no 9.131/95, de 25/ 11/95, a proposta de Diretrizes Curriculares Nacionais para a Educação Profissional de Nível Tecnológico, elaborada pela Secretaria de Educação Média e Tecnológica do Ministério da Educação. A proposta do Ministério da Educação (MEC) apresenta os cursos superiores de tecnologia como "uma das principais respostas do setor educacional às necessidades e demandas da sociedade brasileira", uma vez que o progresso tecnológico vem causando profundas "alterações nos modos de produção, na distribuição da força de trabalho e na sua qualificação". O documento do Ministério da Educação (MEC) pondera que "a ampliação da participação brasileira no mercado mundial, assim como o incremento do mercado interno, dependerá fundamentalmente de nossa capacitação tecnológica, ou seja, de perceber, compreender, criar, adaptar, organizar e produzir insumos, produtos e serviços". Outro item interessante definida pela LDB (Lei Federal no 9.394/96); que comenta a articulação com os demais níveis de Educação; o perfil do tecnólogo; a organização curricular; o acesso aos cursos superiores de tecnologia, bem como a duração, a verticalização, a certificação 
intermediária e a diplomação em tecnologia. Essas áreas profissionais devem ter cargas horárias mínimas, bem como uma rápida caracterização das seguintes áreas profissionais: agropecuária, artes, comércio, comunicação, construção civil, design, gestão, imagem pessoal, indústria, informática, lazer e desenvolvimento social, meio ambiente, mineração, química, recursos pesqueiros, saúde, telecomunicações, transportes, e turismo e hospitalidade. (BRASIL, 2006).

Nesse sentido, o Parecer 436/2001 (BRASIL, 2001) tem como objetivo capacitar o estudante para o desenvolvimento de competências profissionais que se traduzam na aplicação, no desenvolvimento (pesquisa aplicada e inovação tecnológica) e na difusão de tecnologias, na gestão de processos de produção de bens e serviços e na criação de condições para articular, mobilizar e colocar em ação conhecimentos, habilidades, valores e atitudes para responder, de forma original e criativa, com eficiência e eficácia, aos desafios e requerimentos do mundo do trabalho. Segundo o parecer 29/2002, são princípios norteadores da Educação Profissional de Nível Tecnológico: I - igualdade de condições para o acesso e permanência na escola; II - liberdade de aprender, ensinar, pesquisar e divulgar a cultura, o pensamento, a arte e o saber; III pluralismo de ideias e de concepções pedagógicas; IV - respeito à liberdade e apreço à tolerância; V - coexistência de instituições públicas e privadas de ensino; VI - gratuidade do ensino público em estabelecimentos oficiais; VII - valorização do profissional da educação escolar; VIII - gestão democrática do ensino público, na forma desta Lei e da legislação dos sistemas de ensino; IX. garantia de padrão de qualidade; X.- valorização da experiência extra escolar; XI - vinculação entre a educação escolar, o trabalho e as práticas sociais.

Com tais e outros itens anunciados pelo governo, e demanda de mercado, acaba por impulsionar a criação o curso Superior de Tecnologia em Redes de Computadores, surgindo assim um novo desafio de formular o curso, visando o mercado e qualidade de egressos.

Inicialmente o curso tem como espinha dorsal o Projeto Integrador de Disciplinas, que tem a seguinte função básica, interligar todas as disciplinas e colaborar para um projeto maior, que é apresentado no final de cada semestre, essa apresentação acontece até o terceiro termo, ou seja, nos três primeiros semestres há um desenvolvimento de um projeto teórico, integrado e colaborativo entre todos os docentes e discentes. No quarto termo, ocorre mudança de nome desse método para Projeto Integrador de Tecnologias, e atuação do discente, dito de outra forma, o aluno coloca em prática os três semestres de teoria obtida. Essa pesquisa foca as formas de avaliação do ambiente virtual de aprendizagem, importância e carga de trabalhos do Projeto 
Integrador de Disciplina e Projeto Integrador de Tecnologia, desde a criação até o segundo semestre de 2012, comparando com a nova forma iniciada no primeiro semestre de 2013.

\section{RESULTADOS}

Em comparação dos métodos aplicados inicialmente, e o método aplicado no primeiro semestre de 2013. Houve uma melhora com relação ás notas e satisfação no aprendizado por parte dos alunos e consequentemente por parte dos docentes. Essa pesquisa não foi feita nenhuma comparação estatística, e sim embasada na pesquisa teórica de documentos, atas e outros documentos internos que relatam essa satisfação de ambos os lados, docente e discente.

\section{DISCUSSÃO}

Durante as avaliações desde o início do curso até o segundo semestre de 2012, houve vários relatos por parte dos discentes que havia grande variedade de e formas de avaliações, que justificavam algumas falhas no aprendizado do alunado. Feito levantamento e tabulação desses métodos, observou-se que o alunado estava abandonado alguns tipos de avaliações, creditando ênfase apenas em alguns trabalhos focando apenas em tirar nota, dito de outra forma, os alunos estavam escolhendo os trabalhos com maior peso para tentar concluir o semestre. Na visão do aluno, isso foi uma forma de conseguir nota, na visão do docente o aprendizado estava sendo extremamente prejudicado.

Já no novo método em funcionamento no primeiro semestre de 2013 , houve um ganho na satisfação e despertar para o aprendizado do discente. Com relação ao docente, o mesmo também houve melhoras, pois havia grandes dificuldades de cada professor estimar a avaliação subjetiva, talvez ai abrindo brechas na forma de avaliação.

\section{CONCLUSÃO}

A partir dos levantamentos realizados nessa pesquisa juntamente com documentações e história do curso, é posto que:

a) Os discentes estão mais bem amparados com relação à interdisciplinaridade do curso como um todo;

b) As orientações através do curso, de grande parte dos alunos demonstram que existe certa apropriação pelos alunos, no sentido positivo dos estudos, o que mostra o senso da importância metodológica adotada;

c) Dada a diversidade de conceitos definidos na literatura a respeito de variáveis como cyber-espaço, ambiente virtual de aprendizagem, avaliação diagnóstica, avaliação quanti 
qualitativa, avaliação formativa, houve dificuldades para sua captação e organização para se formar como seriam as avaliações de cada ou conjunto de disciplinas;

d) No Projeto Integrador de Disciplinas (PID) e Projeto Integrador de Tecnologia (PIT) demonstra que a maioria dos participantes expressa envolvimento com as atividades e forte organização/liderança interna nas ações;

e) Na visão externa em relação aos alunos, busca a valorização do curso, que proporcionam crescimento pessoal e contribuições na qualificação técnica;

f) O grande diferencial em relação aos docentes é o grande envolvimento dos mesmos em prol a interdisciplinaridade e trabalho em conjunto, tentando atingir o melhor do ensino, avaliação (diagnóstica, formativa) e aprendizagem dos discentes.

Em face ao trabalho e o texto apresentado, acredita-se que a pesquisa representou importantes contribuições para a compreensão e melhorias no Curso Superior de Tecnologia em Redes de Computadores. Quando se realizou o recorte proposto para este estudo, pôde-se observar com mais detalhe a atuação dos docentes voltados à temática "avaliação", maior integração do curso, mudanças no ensino e apropriação do conhecimento por parte do alunado. Apesar de ser um curso direcionado e focado para atender o mercado é possível observar as implicações educacionais que são encontradas na caracterização do perfil do discente motivado no ensino superior, ou seja, demonstra e apresenta na avaliação diagnóstica um movimento de ascensão no contínuo apender.

Acredita-se que o Curso Superior de Tecnologia de Redes em Computadores contribua para o crescimento pessoal, aprimore a qualificação técnica do discente, mostrando o valor nas propostas acadêmicas que tem consciência da responsabilidade com a Instituição de Ensino Superior que o forma. Ainda dentro do conhecimento adquirido ao longo do processo de pesquisa proporciona melhorias na atuação prática que certamente será enriquecida de melhor conscientização. Por outro lado, na visão do docente que tem como ação focalizar o significado e o valor das atividades, que valorizem o esforço e envolvimento do alunado, tendo assim destaque na prática profissional. Com isso, o retorno à sala de aula representa um grande desafio e o compromisso de uma prática pedagógica mais reflexiva. Sabendo que o ensino e a aprendizagem é palco de muitas evoluções.

\section{REFERENCIAS}

ANDRADE F. P. Avaliação da Aprendizagem. Disponível em: <http://www.dominiopublico.gov.br/pesquisa/DetalheObraForm.do?select_action=\&co_obra=86 401>. Acesso em: 26 fev. 2013. 
ATAÍDE, M. I. B. Práticas avaliativas no ensino médio: Estudo de caso de uma escola pública do Distrito Federal. 2004. Dissertação (Mestrado) - Universidade Católica de Brasília, Brasília.

BLOOM, B. S. Manual de Avaliação Formativa e Somativa do Aprendizado Escolar. São Paulo: Pioneira, 1971.

BONNIOL, J. J.; VIAL, M. Modelos de Avaliação - Textos Fundamentais. Porto Alegre: Artmed, 2001.

BRASIL. Ministério da Educação. Conselho Nacional de Educação. Câmara de Educação Superior. Parecer 436. Trata de Cursos Superiores de Tecnologia - Formação de Tecnólogos. Relator: Carlos Alberto Serpa de Oliveira. 02 abr. 2001. Disponível em: <http://portal.MEC.gov.br/setec/arquivos/pdf_legislacao/superior/legisla_superior_parecer43620 01.pdf>. Acesso em: 02 mar. 2013.

BRASIL. Ministério da Educação, Catálogo Nacional de Cursos Superiores de Tecnologia, MEC, Brasil, 2006. Disponível em: <http://portal.MEC.gov.br/setec> Acesso em: 05 mar. 2013

BRASIL. Ministério da Educação, Catálogo Nacional de Cursos Superiores de Tecnologia, MEC, Brasil, 2010. Disponível em: <http://portal.MEC.gov.br/setec> Acesso em: 05 mar. 2013.

CARDINET, J. Avaliar é Medir? Rio Tinto: Edições ASA, 1993.

DELORS, J. Educação: Um tesouro a descobrir. 8. ed. São Paulo: Cortez, 1998.

FREIRE, P. Educação como prática da liberdade. 19. ed. Rio de Janeiro: Paz e Terra, 1989.

FREIRE, P. Pedagogia do oprimido. Rio de Janeiro: Paz e Terra, 1975.

GADOTTI, M. História das Idéias Pedagógicas. 8. ed. São Paulo: Ática, 2002.

HADJI, C. A avaliação desmitificada. Porto Alegre: Artmed, 2001.

HOFFMANN, J. Avaliação Mediadora, Uma prática em construção da pré-escola à universidade. 13. ed. Porto Alegre: Mediação, 1993.

IMMIG, H. Avaliação da aprendizagem em ambientes de Educação a Distância. 2002. Monografia (Graduação Ciência da Computação) - Faculdade de Ciência da Computação, Centro Universitário FEEVALE, Novo Hamburgo.

LÉVY, Pierre. A Inteligência Coletiva por uma antropologia do ciberespaço. São Paulo: Loyola, 1998.

LIBÂNEO, J. C. Didática. 15.ed. São Paulo: Cortez, 1999.

LUCKESI, C. C. Avaliação da aprendizagem escolar: estudos e proposições. 6. ed. São Paulo: Cortez, 1997. 
MAIA, C.; MATTAR, J. ABC da EAD: a educação à distância hoje. São Paulo: Pearson Prentice Hall, 2009.

MEDEIROS, E. B. As provas objetivas; técnicas de construção. Rio de Janeiro: Fundação Carlos Chagas, 1971.

MORAN, J. M.; MASETTO, M.; BEHRENS, M. N. Novas Tecnologias e mediação pedagógica. São Paulo: Papirus, 2000.

MORAN, J. M. Aprendizagem Significativa; Portal Escola Conectada, 2008. Disponível em: <http://www.eca.usp.br/prof/moran/significativa.htm>. Acesso em: 12 mar. 2013.

NOGUEIRA, M. A.; NOGUEIRA, C. M. Bourdieu \& a educação. Belo Horizonte: Autêntica, 2004.

PERRENOUD, P. Avaliação: da excelência à regulação das aprendizagens - entre duas lógicas. Porto Alegre: ArtMed, 1999

SILVA, J. T. Avaliação formativa com suporte de aluno tutor: efeitos no rendimento classificado por nível cognitivo e na satisfação dos alunos. 2002. Dissertação (Mestrado em Educação) - Faculdade de Educação, Universidade Católica de Brasília, Brasília-DF.

SOARES, M. B. Avaliação educacional e clientela escolar. In: PATTO, M. H. S. (org.). Introdução à psicologia escolar. São Paulo: T.A. Queiroz, 1981.

TYLER, R. Princípios Básicos de Currículo e Ensino. Porto Alegre: Globo, 1976.

UNIVERSIDADE DO OESTE PAULISTA. Faculdade de Informática de Presidente Prudente. Projeto Pedagógico do Curso Superior de Tecnologia em Redes de Computadores. PPC-TRC, Presidente Prudente: Unoeste, 2012.

UNIVERSIDADE DO OESTE PAULISTA. Faculdade de Informática de Presidente Prudente. Projeto Pedagógico do Curso Superior de Tecnologia em Redes de Computadores. PPC-TRC, Presidente Prudente: Unoeste, 2013. 